\title{
A Conversation with Grace Wahba
}

\section{Douglas Nychka, Ping Ma and Douglas Bates}

\begin{abstract}
Grace Wahba (née Goldsmith, born August 3, 1934), I. J. Schoenberg-Hilldale Professor of Statistics at the University of WisconsinMadison (Emerita), is a pioneer in methods for smoothing noisy data. Her research combines theoretical analysis, computation and methodology motivated by innovative scientific applications. Best known for the development of generalized cross-validation (GCV), the connection between splines and Bayesian posterior estimates, and "Wahba's problem," she has developed methods with applications in demographic studies, machine learning, DNA microarrays, risk modeling, medical imaging and climate prediction.

Grace grew up in the Washington, DC area and New Jersey, and graduated from Montclair High School. She was educated at Cornell (B.A. 1956), University of Maryland, College Park (M.A. 1962) and Stanford (Ph.D. 1966), and worked in industry for several years before receiving her doctorate in 1966 and settling in Madison in 1967. Although holding several visiting appointments, she has made Madison her home for over 50 years. She is the author of Spline Models for Observational Data which has garnered more than 8000 citations. Grace is treasured as an academic advisor and has mentored $39 \mathrm{Ph} . \mathrm{D}$. students that have resulted in more than 330 academic descendants. She was elected to the United States National Academy of Sciences in 2000 and received an honorary degree of Doctor of Science from the University of Chicago in 2007. Wahba is a Fellow of several academic societies including the American Academy of Arts and Sciences, the American Association for the Advancement of Science, the American Statistical Association and the Institute of Mathematical Statistics. Over the years, she has received a selection of notable awards in the statistics community: R. A. Fisher Lectureship (2014), Gottfried E. Noether Senior Researcher Award (2009), Committee of Presidents of Statistical Societies Elizabeth Scott Award (1996) and the first Emanuel and Carol Parzen Prize for Statistical Innovation (1994).
\end{abstract}

Key words and phrases: Spline, reproducing kernel Hilbert spaces, RKHS, Wahba's problem, cross-validation, generalized cross-validation, support vector machines.

The following conversation took place with Douglas Bates, Ping Ma and Douglas Nychka at the University of Wisconsin-Madison on December 10, 2018.

\footnotetext{
Douglas Nychka is Professor, Department of Applied Mathematics and Statistics, Colorado School of Mines, 1500 Illinois St., Golden, Colorado 80401, USA (e-mail: nychka@mines.edu).Ping Ma is Professor, Department of Statistics, 310 Herty Drive, University of Georgia, Athens, Georgia 30602, USA (e-mail: pingma@uga.edu). Douglas Bates is Emeritus Professor, Department of Statistics, University of Wisconsin, 1300 University Ave, Madison, Wisconsin 53706-1685, USA (e-mail: bates@stat.wisc.edu).
}

\section{EARLY YEARS}

Nychka: Let's start at the beginning. Were you always interested in mathematics or did that come later?

Wahba: In the ninth grade, I was enamored of algebra and I was determined to get all the problems done. My mother used to come up to the bedroom where I was working, and she said,"Grace, it is time to go to bed," and I would say "No, I'm not going until I finish this problem." That was very unlike the behavior of a young girl at that time!

Nychka: Wow, I guess that interest just stayed with you. Was it just mathematics or was it other kinds of science as well?

Wahba: Well, also physics. Later in high school, I was the only girl in the physics class. There were four guys 


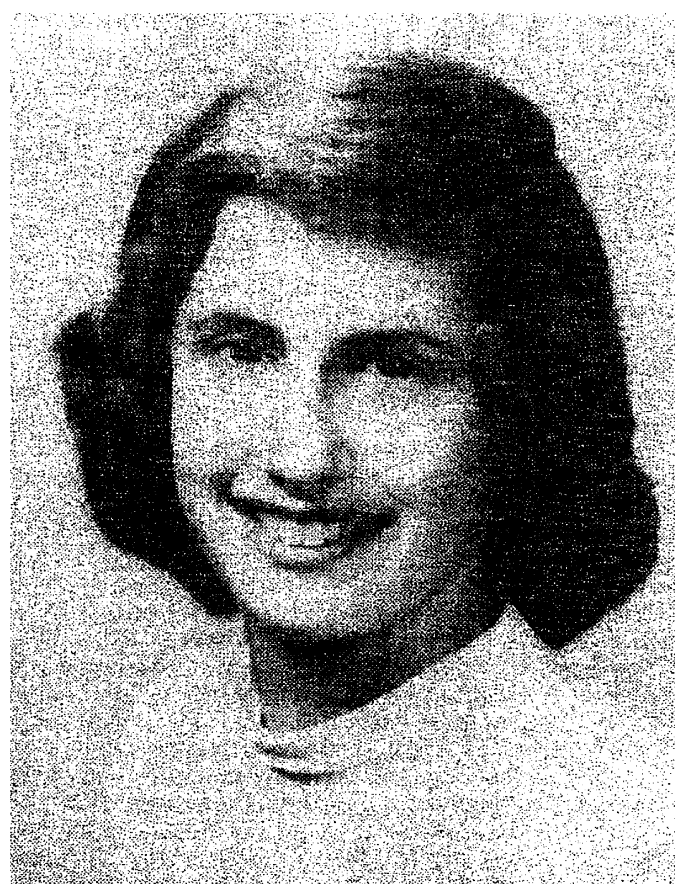

FIG. 1. From the 1952 Yearbook, Montclair High School, New Jersey.

that sat in the back of the room harassing the teacher who was an old person, at least to us, and he did things like roll up his left sleeve but put his right arm in the bucket of water. I was trying hard to understand what was going on, but when he got to "per second per second," it was sort of a bust, because none of us knew what a derivative was. This teacher's name was Mr. Ladd. Later the four guys had formed a little club, called "Mr. Ladd's Make Up Exam." They met every year in Pennsylvania, and for the twenty-fifth anniversary of this little club, they invited me to join and I was thrilled.

Nychka: After high school, how did you decide to stay in mathematics, or did you want to do something different?

Wahba: Well first I have to go back a little bit earlier. Sometime when I was in high school I decided that I did not want a career as a housewife. I wanted to do something where I could have a professional career and get a real paycheck. But I had no idea that you could do that with mathematics. When it came time to go to college, I applied to four places. Three of them were in the Washington, DC area, where we had lived before moving to New Jersey, and I was very interested in going back there. The fourth place I applied to was Cornell and the reason was because of a young man that I was dating at the time. $\mathrm{He}$ was a freshman at Cornell and I had no idea what Cornell was like except he was telling me how wonderful it was. Everybody in my high school was shocked that I actually was admitted, because except for math and physics, I found high school very boring. Somebody told me that you had to get B's to get into college, and so I was very careful and did just enough work to get B's in English and history and all that other stuff. I didn't have much of a grade point average except I had aced math and physics. The creepy guidance counselor, who gave me an undeserved $\mathrm{C}$ in French, told me not to bother applying since I'd never get in. But I did get into Cornell and people said, "That's wonderful." The young man said, "That's wonderful," and then I went. Of course, after I got into Cornell, I found that he was dating somebody else. But here I was at Cornell and was suddenly aware that this was one of the very few places at that time that a woman could study mathematics under some of the world's greatest mathematicians. Brown was the only other Ivy League school that admitted women at that time. That was one of the first lucky breaks in my life. The first professor I talked to was J. Barkley Rosser, who later joined the faculty at Madison.

\section{WOMEN AT CORNELL}

Ma: I can imagine that it must have been tough for a woman to pursue a career in STEM in America.

Wahba: I was in Cornell from 1952 to 1956 and first signed up as a math major. But first let me go back to high school where five of us were invited to participate in a special math class, which was built on probability, and we learned some combinatorics. But as a result, I did not take trigonometry in high school. I got to Cornell and J. Barkley Rosser was there at a reception for new prospective math majors and he asked me what I was taking. And I said, "Well, I did not get trigonometry in high school, so I'm going to take trigonometry and then calculus and then I'll take English and history and the other stuff." He told me that I should take calculus with the trig or I would be behind all the other math majors. Well, I did and it turned out that trigonometry wasn't exactly hard for me. I got a 99 in trigonometry and a 98 in calculus. Those numbers were very hard to get. Nobody ever got a 98 in history, for example, and I made the Dean's list. The English professor who gave me a 75, a C grade, asked, "How did you get on the Dean's list?" So I had to tell him that I have a 98 in calculus and a 99 in trigonometry. That was my claim to fame that I made the Dean's list my first semester at Cornell and it was a big deal.

Nychka: Did the rest of your math major go smoothly?

Wahba: Now there are two tracks to this story. One of them involved a woman named Vida in Civil Engineering, the only woman there. I had no idea that you could actually earn a living in mathematics but I thought, well if you get an engineering degree, certainly that's a ticket to a real career. So my original plan was to spend the first semester in math and see how well I did, since engineering was believed to be very hard. Well, since I made the Dean's list, I thought I'll switch to engineering. But I had missed all 
the orientation information that they gave the engineers, and I had no idea which engineering I wanted to take.

There were five engineering schools there. Here's where Vida comes in. Vida was in Civil Engineering and she said, "Grace you've got to get into Civil. Take civil engineering, and it is wonderful." I was a bit clueless but I left Arts and Sciences and I was accepted into Civil Engineering. In the first semester, there I took surveying and drafting as required. Surveying wasn't really that exciting, and I was paired with a basketball player who was forever on the road playing in games, so I got to handle this surveying equipment without a partner. Civil Engineering had a summer survey camp, where you went off to the countryside somewhere, and you practiced surveying. Well, I didn't really know it at the time but surveying around a quadrangle without a partner is difficult. I never got my surveys to close.

Nychka: Does that mean they never matched up?

Wahba: Right, that is when start and finish are supposed to meet around the quad, and my numbers did not match very well. I had to carry all the survey equipment by myself, while this guy is always playing basketball. Another part was drafting. Drafting in those days was pretty hard. You had tools and an inkpot, and if you made mistakes, you had a little razor to fix them. Somehow it wasn't for me. Also, I would come to the drafting room for class and outside the door, I hear all these guys are laughing and roaring and stuff. I came in and it would fall completely silent. And I said, "What are you talking about?" And they would say, "Not for your ears, Goldsmith." They were telling dirty jokes. I thought it was funny but the end result was that I decided that civil engineering wasn't for me and I switched back to be a math major. Afterward, I heard a lot of rumbling because there are no women's facilities in the survey camp. Vida had dropped out and so there was a lot of groaning about having to build a special outhouse for Grace Goldsmith. Anyway, I got back to mathematics. On the basis of my stellar 98 grade, the eminent mathematician, Mark Kac, had a special class for people who he apparently thought had promise. I guess there were thirteen of us, including one other woman, Diane Finegold, and he seemed pleased that we were in his class. She and I would go in and talk to Professor Kac, who was the advisor to both of us, for our first three years, until he went on sabbatical. And he was very friendly and encouraging and so forth. Diane graduated and went on to serve in the White House for Evelyn Lincoln, who was John F. Kennedy's secretary. The Cornell Alumni News of 1970 has her teaching philosophy at a community college near Washington. Of the other people in that class, there were two that I'll mention. One of them, Gordon Baym, went on to an academic career in physics. The other one was a friend by the name of Bob, who I was chummy with. I thought Bob was a genius because he never appeared to do any work, and after class, he went down to
Collegetown and drank. I thought "My god how can you do this class when you don't even turn up?" I had assumed it was easy for him. Turned out he might have been really smart, but he never did any work. And 10 years later, I got a communication from him regretting that he had wasted his talent and was sorry for that.

To string some things together, Mark Kac left on sabbatical my senior year, so I had to find a new adviser. J. Barkley Rosser was there, and I asked him to be my advisor. He was very different. He was all business, unlike the ebullient Mark Kac. I had gotten married at the start of my senior year, and I told Professor Rosser that I was kind of overloaded with work, being married, and working in my husband's lab during class breaks washing bottles. Furthermore, I was pregnant and I had to take a lighter load. He didn't say anything and he just signed the form. That was okay.

Many years later, when I got to Madison, I found he was on the faculty here. I remembered him pretty well, but I don't know whether or not he remembered me as a former Cornell student. However, I was appointed to a cushy part-time research position at the Mathematics Research Center (MRC) where he was director, and he was very supportive of my being at MRC.

\section{A FIRST JOB}

Ma: After Cornell, I guess you ended up with a job, a real job?

Wahba: Actually, it wasn't that simple. As I mentioned, I got married at the start of my senior year. My son was born two months after I graduated. The downside was that the marriage was not good for me. I spent the summer after my son was born with my parents and moved to Bethesda, Maryland, in September, where my son's father had a post doc at the National Institutes of Health (NIH). I was home with my son for about six months, but the playground chats about when to switch the babies to winter underwear were not very fulfilling. I wanted to start back in graduate school, but my husband did not want me to do that. He was working at NIH in Bethesda and we lived within a few miles. There were a couple of women in his lab, but mostly the wives were stay-at-home moms. They all queued up in their cars in the NIH driveway at the end of the workday with the mothers and their children dressed in their best and waiting for the dads to come out. He wanted me to be there showing off his kid along with all the other families.

I had an arrangement where my friend Priscilla babysat my son when I went over to the University of Maryland, College Park, where I wanted to go to graduate school. They had classes like our 709 (graduate level mathematical statistics) at 4 o'clock in the afternoon, so the government employees could do that, but I couldn't join the parade in front of NIH and be in College Park, which was an 
hour away. So I couldn't get to that class. My husband demanded that I show up in the driveway line with our son, although he could have easily carpooled with the husband of my friend Priscilla or taken the bus home. Priscilla and her husband lived in the same building as we did.

Ma: How did you get around this?

Wahba: I went out to College Park and talked to somebody about what I might be able to do as far as graduate school. I knew I could not take the 4:00 class. But the faculty member who talked to me had recently graduated from Cornell with a Ph.D. from Mark Kac-of all the good luck! All I had to do was to tell him that I was in Professor Kac's special math class. Also, I taught a calculus class not as a TA but as an instructor when I was junior at Cornell all on the basis of that wonderful grade in calculus. When I told him all this, he hired me on the spot to teach a remedial math class which I could do at 1 o'clock without disturbing my husband's interest in seeing me in the kids' driveway show. That was another piece of luck; at least I got out of the house. Rather than join the chats in the playground, I was trying to work my way through Van der Waerden [15], but that was a lonely operation. After I taught remedial math for a while, I decided that this wasn't exactly what I wanted to do either.

Nychka: These are great stories, Grace. How did you finally get your job at Operations Research, Inc.?

Wahba: Well, around this time there are several long stories about my former husband that I won't tell. To summarize, we separated. He finished his post doc and moved to Boston, but I refused to join him. I got a job before he left. I told him I wanted to get a job. He was on a post doc salary and so, he thought, that as long as I am earning some money, he wouldn't mind my taking the car to get to work. My first job was at a company called Operations Research, Inc. (ORI), as a human calculator. We had an electronic machine with buttons, and you punch the buttons, as a human computer. I was interviewed by Ritz Hare who turned out to be a wonderful mentor. He said we were doing this job which involves integration, so he gave me a test. He said, "Just apply Simpson's rule." As an undergrad, I had registered for Rosser's numerical methods class, which started out with numerical quadrature using desk calculators. I left the class after about a week because the last thing I wanted to do was to punch those calculators. But here I was offered a job doing numerical quadrature, exactly why I left Professor Rosser's class. Anyway, I wanted a job. So I said, "Well, I don't know what Simpson's rule is, but if you tell me what it is, I can try to make it work." He told me Simpson's rule, put me in a room with a desk calculator to do an example, and I was hired.

I worked in the back room with two other women who also punched calculators. In the front, there were all the staff scientists, some had Ph.D.'s and some had engineering Master's, and some of them had exactly the same education I had. Their jobs allowed for setting problems up and then asking me to do the numerical calculations. Some of the staff were not actually that knowledgeable. Anyway, I got this job and had a steady paycheck. One staff member just came in asking me to compute this, compute that, and his description didn't make any sense to me. I asked him, "What are you doing? What are you trying to do with this?" He told me. And I said, "If you do it this way, it would be much better." I taught him how to solve his problem so that I did not have to compute the numerical quadrature. Apparently, later Ritz, who had originally interviewed me, managed to get me moved to the front of the room with the engineers. So Ritz was very helpful. ORI did various mathematical or analytical projects. I became an expert on medical aid battalions and helped develop strategic battlefield plans. During the course of work, I read some classified documents about licensing ladies of the night! After several years, I guess I was there for almost five years, I was sharing an office with a guy who was very ambitious. We used to chat about our projects. At one point, he was involved in writing a proposal and he was out of the building or something. I' $m$ not ordinarily a snoop, but I knew that I had been talking to him about the stuff that was going into his proposal. There were the proposal and budget on his desk, and so I looked at it. It turned out that he was making ten grand. I was making five grand and he was stealing my ideas, and putting them in his proposal as his own! I was very angry but I did not say anything but thought, "Now is time for me to get out of this."

\section{WORKING FOR IBM}

Wahba: IBM was advertising for people in Washington, and it was closer to where I was living. So I went over to IBM and I was hired. I came back and talked with the vice president of ORI. I said, "I am handing in my notice because my roommate is making ten grand," but I didn't tell him he was stealing my ideas. We were basically doing the same thing. He kept saying, "Don't take it, don't take it, we will fix it." Well it was too late and I left. My job at IBM paid ten grand and I had the satisfaction of telling him that. We were in a building which had the IBM 7090 consisting of the entire first floor with 32,000 vacuum tubes but I didn't use it. I wasn't hired for my programming skills since I didn't have any. My father said to me, "You got a job at IBM?" He said, "They never hired Jews." That was the old T. J. Watson. But T. J. Watson, Jr. was much more egalitarian, and so there were four of us who were kind of misfits, but we all hung out together.

Ma: Why do you say you were misfits?

Wahba: There was me; there was a black guy, Nate Woodrick, who was a meteorologist; there was a Mexican guy who was about $5^{\prime} 0^{\prime \prime}$ tall; and then there was a 
white guy, who was about $6^{\prime} 5^{\prime \prime}$ and weighed several hundred pounds. When we first became friends the idea was to take turns choosing where to eat. When my turn came up, I chose a particular restaurant and one of the other men took me aside and said to pick another place, that one wouldn't serve Nate. They didn't serve black people at the time. That was just how Washington was: it was a Southern city.

\section{STATISTICS AT STANFORD}

Nychka: How did you end up at Stanford?

Wahba: As you listen to this story you will realize that I was incredibly lucky at many different times. First of all, I did manage to get a Master in Mathematics while I was at ORI despite my ex-husband's constraints. I had sued him for divorce in Maryland soon after he left for Boston. The grounds for divorce in Maryland were only adultery and desertion. He claimed that I deserted him and not the other way around and he wanted me back. Other things had no legal standing. To make a long story short, the divorce petition was denied, and only a legal separation granted. The lawyer told me if I ever want to get a divorce I would have to go to Florida or Las Vegas where you could establish residency in six weeks, or do the same in California after a year's residence. But I didn't see how I could do that. I would have to leave my job and maybe my son. Just in time, IBM moved our whole group out to San Jose, California, and then shortly to Palo Alto, right up the street from Stanford. There I could also get a divorce. Not only that, IBM had a work-study program at Stanford. I did my Ph.D. part time on that. Part of it was to work 30 hours a week and have 10 hours a week of classes at Stanford. They paid the tuition, so I was never a TA there.

Nychka: But you were still a single mom and managing a job?

Wahba: I was still a single mom and still managing a job.

Nychka: Amazing.

Ma: Grace, I'm curious how did you choose Manny (Emanuel) Parzen as your adviser?

Wahba: Back when I was in Maryland and I had just moved to the front of the office with the engineers, I read Manny's book Modern Probability [13]. I loved it. I had another book of his, Stochastic Processes [14]. And I thought it would be great to go out to Stanford and have this guy as a thesis advisor. (But it was just a dream then.)

Nychka: At that time, what was the atmosphere among the Stanford graduate students?

Wahba: My Stanford class was full of currently famous people including Brad Efron, Carl Morris, Mike Perlman, Steve Fienberg, Jay Kadane, Krish Athreya and others. I know there were fifteen of us that graduated around the same time. Anyway, it was a bunch of really smart people.

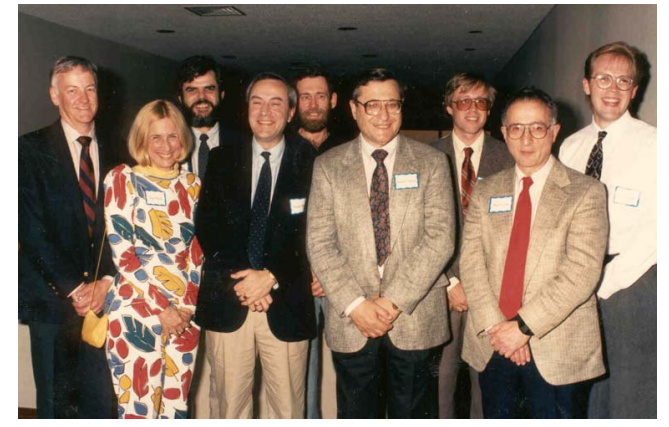

FIG. 2. Manny Parzens's 60th Birthday, 1989. Left to right: Don Ylvisaker, me, Joe Newton, Marcello Pagano, Randy Eubank, Manny, Will Alexander, Marvin Zelen, Scott Grimshaw.

I had the feeling that I was not at the bottom, but I certainly wasn't at the top. But I felt that I was somewhere in there and that was quite an accomplishment.

\section{WAHBA'S PROBLEM}

Ma: Can you tell us a little bit about "Wahba's problem" [16]?

Wahba: After I got out to the West Coast, I was taking a multivariate class from Ingram Olkin and working at IBM. I was on a couple of satellite projects and what came across my desk was the problem of orienting the satellites.

Say you wanted a camera to be pointed toward a feature on the moon. Well, you had to know the satellite's attitude to do that. A set of selected stars is available whose direction cosines from the satellite are known. The satellite has a bank of star sensors that also observe apparent direction cosines of these stars in the satellite coordinate system. The goal is to rotate the satellite so that the observed direction cosines best matched up with the actual direction cosines.

Wahba's problem was to find the rotation matrix that would best do that and it came across my desk at IBM. Using what I learned in Ingram Olkin's class, I eventually figured out how to estimate the best rotation matrix in a certain least squares sense. It was sort of trivial except that there's a minus sign that you have to resolve and gives it an extra twist. I submitted it with a solution to SIAM Review [16], and that is why it is called "Wahba's problem." They didn't print my solution, however, because SIAM would print the proposer's solution only if no one from the general public responded with a solution. There were several solutions and they printed one of them [17]. I didn't know that the problem was called Wahba's problem even though the printed solution was somebody else's. That is Stigler's law of eponymy. The person who invents something is never the one named for it. What was worse, it came out some years later. One of my advisors in University of Maryland, George Weiss-I was talking to himhe told me that he had solved Wahba's problem in $n$ dimensions in some physics journal. I didn't think about it 


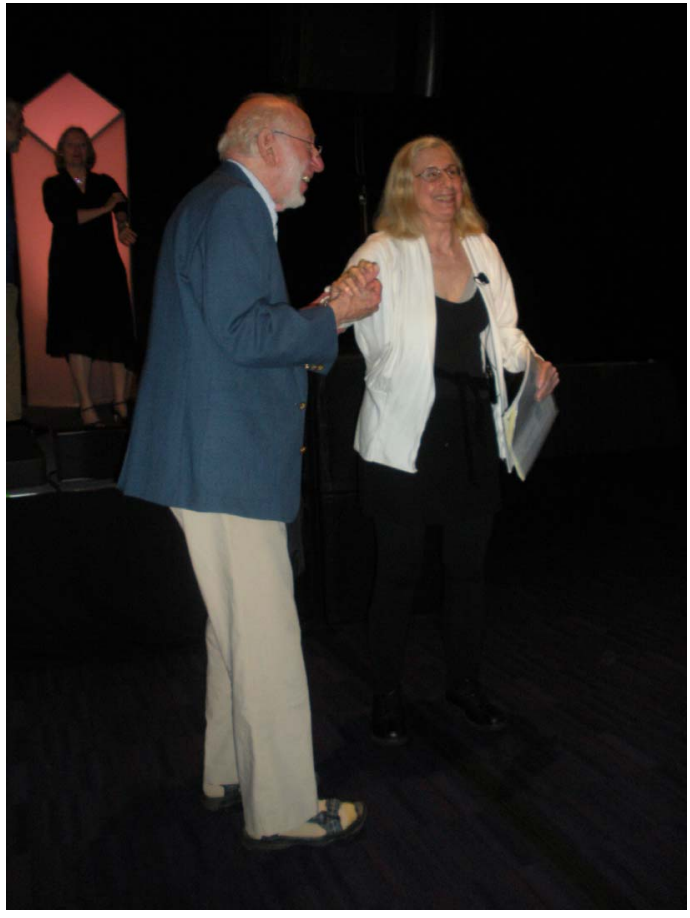

FIG. 3. With Ingram Olkin, JSM, 2014.

for many years, but then, about 15 years later, I was visiting Yale and someone walked in to my office and said that they heard that Wahba was here. He asked, "Are you Wahba? Yes, I am Wahba." He said that he just want to see somebody who solved Wahba's problem. I was like, Wahba's problem, what was that?

Ma: Oh, I see, that was the first time you knew it was called Wahba's problem.

Wahba: Yes, a complete surprise. After that came about, I was invited to write about its history. I tried to track down George Weiss's article and then him. I tracked him as far in NIH, but apparently he had retired and nobody knew where he was. So, that was an example of Stigler's law.

\section{UNIVERSITY OF WISCONSIN}

Nychka: You have been at Madison for much of your career. How did you get here?

Wahba: I had a post doc with Manny Parzen and I didn't want to go back to my group in IBM. I felt I was sort of overqualified by the time I got a doctorate. IBM did offer me a job at Yorktown Heights at a salary that was about $50 \%$ higher than what assistant professors were going for. That was $\$ 18,000$ and the assistant professors were going for about $\$ 10,000-12,000$ in 1967 . I actually received seven offers besides IBM. A couple of them really weren't serious in that they didn't invite me for a talk. They just sent me a letter offering me a job. I gave a few job talks with a talk here at Madison in the winter. I had only high heels, no boots. The weather was miserable but here comes a boyfriend again into the picture.
There was a guy in the physics department at the University of Maryland, who I was dating, but he was here for the summer before I went to the Madison job talk. I had come out to see him and it was beautiful! Madison is so pretty in the spring and summer. This is a fantastic place. So when I came in January for a job talk, I didn't mind walking around in six inches of snow in my high heels and my IBM business suits but I was a little bit out of place. This wasn't the best offer money-wise that I got, but it was the combination of one thing to live in Madison and the other that everybody in the department was very friendly. There were three of us having post docs at Stanford, John Van Ryzin, they made an offer to him first but he turned it down and went to University WisconsinMilwaukee. They made another offer to the second guy and he turned it down and went to some not so famous school that offered more money I guess. Van Ryzin eventually left Milwaukee, however, and he came here and was later department chair.

Ma: You were actually the third person on the department's list?

Wahba: Yes. I think Rich Johnson came here the year before me. George Box was here. Anyway, so there were four of us close together as assistant professors: Rich, myself, Steve Stigler and Gouri Bhattacharyya.

Bates: Do you have any memories about your time as an assistant professor?

Wahba: Yes, I have a few stories. The department was seven years old in 1967. George Box was the [original] Chair and he built the department. He found out I was interested in tennis and personally phoned me to tell me about the new tennis stadium. George Tiao and Bill Hunter were here and Norman Draper was later Chair. At that time, they had a Friday night poker game. George Tiao lived near me at the time and Van Ryzin lived up the street from me on Tally Ho Lane. George Tiao invited me to join the Friday night poker game, and I thought that was so sweet.

Nychka: How did you do? I see you being a sharp card player.

Wahba: Well, I was married to my second husband, Ramon Moore at the time. I said, "Ray, I've been invited to play poker; how do you play poker?" I knew how to play 21, but I asked what else did I need to know. He said, "There are a lot of ways to play poker. Somebody will call the game." I walked up to the game with my five-dollar bill for the maximum stake. Somebody said something I think they were announcing which game of poker was next. I had no idea, so I just kept what I thought was a poker face. Everybody thought I had something. When I turned over my hand someone cried out that she doesn't have anything. I never went back to the poker game, because I never learned how to play. But it was such a sweet reception and I appreciated it. The other memory was that 


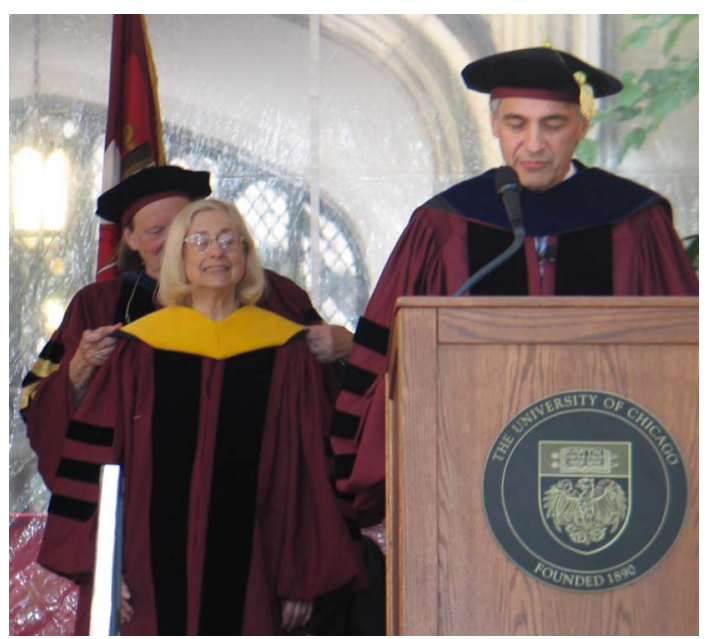

FIG. 4. Receiving the honorary D.Sc. hood, University of Chicago, 2007.

everybody was hot for hockey. I thought if I want to join the lunchtime brown bag conversation, I better know what is going on. I read all the newspapers and found out who the big hockey players were and so joined the conversations. Growing up, my father was an accomplished amateur tennis player and spent a lot of time teaching me tennis. He said that it was a great sport for making social and business connections. After I arrived in Madison, Norman Draper, Michael Akritis and a Swedish woman friend of Michael's were looking for a fourth for mixed doubles and I fell right in. At that time Norman was Chair, and so I had a social connection to the Chair not typical of an assistant professor.

\section{SPLINES AT THE MATHEMATICS RESEARCH CENTER (MRC)}

Nychka: I would like to hear how the Kimeldorf and Wahba work came about.

Wahba: Our most important paper contained the Kimeldorf-Wahba representer theorem [5], although the names aren't commonly attached to it that way. That was an important theorem, and a big deal. We earlier wrote two papers [6, 7] about zero mean Gaussian processes and corresponding RKHSs associated with linear differential operators.

Ma: How did you get to that topic from your background in time series?

Wahba: When I was at Stanford, my thesis was on time series. Manny Parzen talked about reproducing kernel Hilbert spaces (RKHS) and I thought they were fascinating things. When I was at Maryland, I took a course in functional analysis and I just ate up all the different kinds of function spaces. In Maryland, however, the professor didn't talk too much about RKHSs, but I just thought this functional analytic stuff was really something. Then when I got to Stanford, Manny was talking about RKHSs. I realized there was something special because reproducing kernels were the natural generalization of a positive definite matrix, in an extremely general way. George Kimeldorf and I both had lower teaching assignments because we had appointments at the Math Research Center. We just were doing a lot of talking. I'm trying to think about when it actually started but I'm not a hundred percent sure I got this right. Iso Schoenberg had talked about the cubic splines and I was aware that he had the solution to the problem of minimizing the sum of squares of the differences between fitted points and data points plus squared second-order derivative as a piecewise polynomial satisfying continuity conditions. He used only elementary methods, like integration by parts, to prove this, not Hilbert spaces. So George and I got to talking. We got clear that we could solve that problem in the context of a RKHS, and once you did that you could see how to solve a very large class of optimization problems by the same methods. Of course, you had to know what RKHS was needed. But once you did that, the problem generalized to any RKHS, not just the one associated with a cubic spline. We started talking about writing a paper. I said, "It's trivial. Can we publish a paper about that?" He insisted, and our paper [5] was actually accepted in three weeks, faster than anything I wrote before or since!

Nychka: How did you and George think of that association? It is an amazing result.

Wahba: George had learned about RKHS theory somewhere before he came to MRC. So did I. We knew that we could write the problem down and the representation for the representer. If you both know reproducing kernel spaces, then it is pretty quick to figure that out.

Ma: Do you know if Schoenberg ever commented on this or congratulated you?

Wahba: He was there but he was already in his 80 s. He wasn't doing much then but we had a few brief discussions with him at the start. MRC was a hotbed of numerical methods, however, it wasn't just Schoenberg. Carl de Boor was the leader, Larry Schumaker and other luminaries were there including a couple of other people that were into splines. At 11 a.m. and 3 p.m., we all gathered for tea.

Nychka: I recall in one of your papers you acknowledged the ministration from a tea lady in the Commons Room when you were visiting Oxford University.

Wahba: Yes, tea at 11 and 3 is a well-known English tradition, and later at Oxford on my first sabbatical, I really enjoyed it. The tea at MRC was also a big deal. Everybody gathered in the tea room twice each day and tea was served by the MRC staff. It was great for forming collaborations and socializing. One collaboration was with Zhuhair Nashed on ill-posed inverse problems that also had the benefit of motivating some related solo research [18].

Nychka: Grace, with your collaboration with Kimeldorf, being part of MRC, and the emphasis on numerical 


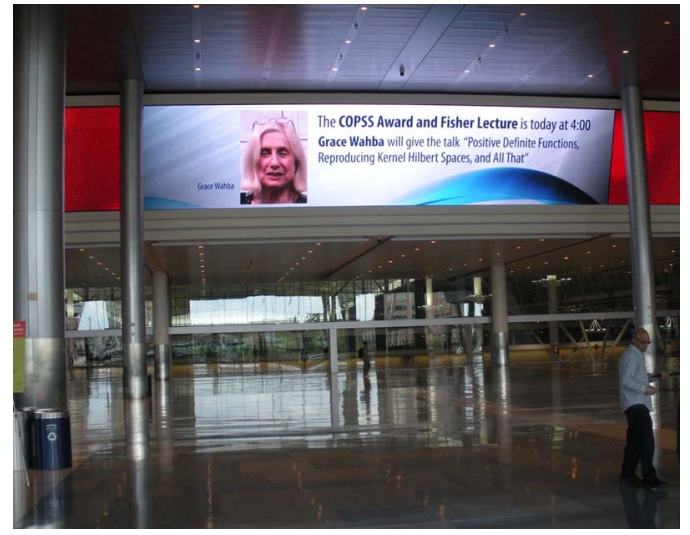

FIG. 5. Announcement of Grace's Fisher Lecture, Joint Statistical Meetings 2014, Boston, MA.

analysis in your early career, did people wonder if you are doing statistics, or did they think of it more as applied mathematics? Did you worry about getting labeled not as a statistician?

Wahba: MRC was populated by big shots in numerical methods, but nobody put a label on what we were doing. In fact, there are connections between certain numerical methods and different kinds of regularization. For example, early stopping in iterative methods for solving a linear system can have a regularizing effect similar to that of penalty methods [19]. Well, it was an interesting environment.

There was another woman, Nira Dyn, a mathematician and numerical analyst, and we wrote a few papers together. Back in those days, there were very few women that were working at the university. The wives of all the men had a ladies community. They had tea also and they invited me and Nira. We really didn't know what to do. We thought it was so nice of them to invite us, but on the other hand, we discussed it between ourselves and we said, "Well you know we're being paid to work eight hours a day, and we probably shouldn't take off the middle of the day for social reasons." So we declined with thanks. J. B. Rosser, he was at Madison as I mentioned. He and his wife Annetta threw a lot of parties for everyone and, of course, we went to those.

\section{GENERALIZED CROSS-VALIDATION (GCV)}

Ma: Tell us how you discovered GCV?

Wahba: There are two early papers from two slightly different perspectives. Golub, Heath and Wahba [3] and Craven and Wahba [2]. Before that, there was the automatic French curve paper [22]. Are you familiar with that one, Ping? That was an old one!

But let me go back before Golub, Heath and Wahba [3], Craven and Wahba [2], or Kimeldorf and Wahba [5]. All were significant collaborations, but earlier I remember sitting together with Svante Wold in a talk in the department given by Mervyn Stone. He was fitting polynomials by least squares and the question was what order of polynomial should he use. He was doing leaving out one (cross-validation) against the predicted mean squared error to see when you should stop adding polynomials. We are sitting next to each other, and literally we said, "Eureka!" We figured out how to apply that to the cubic smoothing spline and Svante wrote some programs to see how well it worked. In Madison at that time, we had this big computer, where you punched your code, the FORTRAN code, into Hollerith cards-this was 1974-and handed the cards in at the desk. Then you came back two days later, to get the output and they often told you that your code didn't run. This computing was pretty expensive, it cost about a few hundred dollars an hour. The department had a budget to use this machine but we ended up using the entire statistics budget for the month to check leave-one-out cross-validation for doing cubic smoothing splines. It was clear that it worked somehow and I guess it was worth it in hindsight to spend that. But when I was trying to prove it, I realized that in the general case, you can rotate your data and your white Gaussian noise and it is still white Gaussian noise. So the problem should be invariant under rotating the data and solving the spline problem by observing noisy rotations (orthogonal linear combinations) of the function. That is the case only if the influence matrix is constant down the diagonal. In fact, it is easier to compute the trace of the influence matrix and the trace is invariant to rotations. That led me to GCV.

\section{A KNACK FOR COLLABORATION}

Ma: You did this theory on cross-validation and then things just exploded in terms of applications. How did that happen?

Wahba: As soon as we learned something about the tuning parameters, that led right into the old inverse problems. Doug, you have the most fabulous ill-posed inverse problem with your analysis of the mouse liver tumors data [11]. That was the analysis of experimental data that included walking through the lab to see the source of anomalous data, setting up an ill-posed inverse problem to obtain the desired tumor distribution, and providing a new and appropriate numerical approach to solving it. Then Finbarr O'Sullivan was also working on an inverse problem for the atmospheric vertical temperature distribution [12], with Professor Don Johnson and other people in atmospheric sciences.

Doug went through this lab where they had mice and they were giving them diethyl nitrosamine, sacrificing the mice, looking at tumors in their livers, and relating the tumors to the doses and time since ingestion. Standard pathology methods used in cancer research. But they were getting answers that didn't make any sense to them; the tumors were all flattened, not spherical. They were trying to figure this out from just the tumors. Maybe there was 


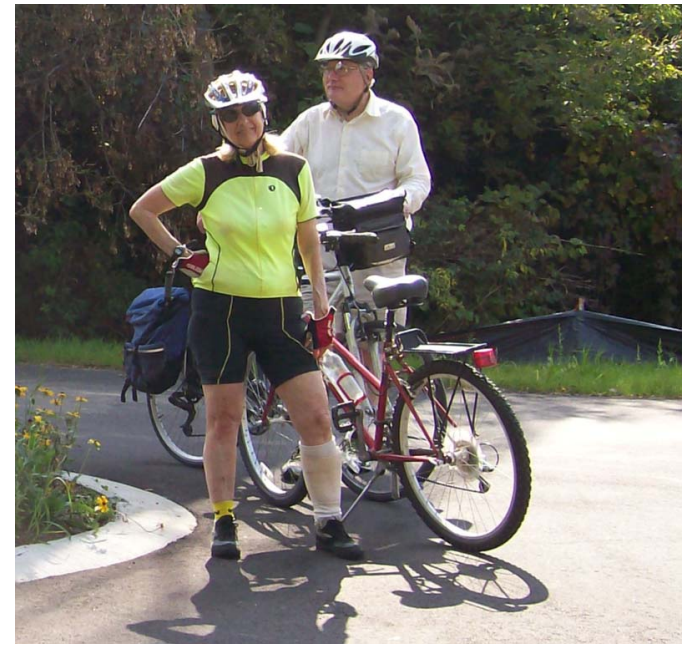

FIG. 6. With David Callan on a bike trip, Germany, 2017.

some complex mechanism in the tumor growth and they growing in funny ways.

Nychka: I remember we solved this using a classic Box, Hunter and Hunter [1] approach. Where if you want to learn something you design a little experiment to answer it. Grace and I were able to convince them to process the mouse tissue in a way where you know what the answer is supposed to be. They actually processed small perfectly spherical beads embedded in paraffin like the mouse tissue. They found these were also distorted and so we used a simple regression to set up a correction.

Wahba: There was another Box, Hunter and Hunter idea in this project. We were suspicious about the reproducibility of tracing the tumors by hand under a microscope and we suggested that they get some of these to be drawn twice like a blind study. The researchers came back and said they could not ask the lab assistants to do that because then the staff won't trust them. They had a post doc do one of the trials, however, and sure enough there was a bias on how things were drawn.

Nychka: We made the collaboration for the mouse experiments through Joshua Chover (a probabilist) over in the Math Department. How did you develop the contact for Finbarr to work with Johnson?

Wahba: Don Johnson was on a university committee that met on Saturday morning. I was on the same committee, and our offices were across the street from each other then. The first thing that we talked about walking back from the meeting was this problem of spatial data, the meteorological observations, being spread around irregularly. The numerical weather prediction models at the time were mostly grid point models. They adapt differential equations to a fine grid, so you had to estimate the state vector, the temperature, pressure and so forth on the grid points. They had something called optimal interpolation, which was not optimal and it was not interpolation. It was an inverse distance weighting scheme that was pretty bad. We soon realized that something better than inverse distance was needed. So Don became my meteorological tutor. He was very generous and I spent a lot of time learning about numerical weather prediction models. The first paper was part of Jim Wendelberger's thesis [21]. One of my first meteorological papers with Don [4] was a real joining of statistical and meteorological expertise. For Finbarr's work, the satellite radiance data and upwelling radiation was measured from satellites that were designed by the Space Sciences and Engineering Center, SSEC, just across Dayton Street from the Statistics Department.

Nychka: When you wrote the Craven and Wahba paper and were working with Wold, I think of that as a turning point where your research really became dependent on computing as one of its components. But you did not do much coding yourself.

Wahba: From my early experience at IBM, I was the algorithm person and I had five programmers working for me. So I had no motivation to learn any computer programming. I taught myself BASIC at some point and I knew about six FORTRAN commands. The rest of the group did all the computing but I had to train myself to understand what the answers ought to look like. That way I could develop confidence in their work, however, hazy it was. I always had some idea of the result and I didn't give anybody a problem unless I had some feeling for what the answer should look like.

Bates: Nevertheless, you've had many many successful students who have done lots of computing.

Wahba: That's partly because I was not good at it! I really depend on my students.

\section{SPLINES AND SUPPORT VECTOR MACHINES} (SVMS)

Ma: In the next chapter of your research, you started doing machine learning before anybody knew it was machine learning.

Wahba: Well, that depends on how you define it.

Ma: Bin Yu mentioned that you were her role model. I am interested in your thinking about how to structure a machine learning problem in a mathematical way.

Wahba: Well, I didn't know that. As far as I am concerned, Bin is a genius and an amazing person. She does a lot of different consulting projects, wrote some major theoretical papers, chaired the Berkeley Statistics Department and was the President of the Institute of Mathematical Statistics (IMS).

Ma: Tell us how you got interested in the connection of splines to classification and to SVMs.

Wahba: Vladimir Vapnik invented SVMs. It had to do with maximizing the margin, I could tell you how he did it, but it has nothing to do with RKHS or anything like that. But it worked amazingly well. I was friendly with Olvi Mangasarian, who was in Computer Sciences here, 


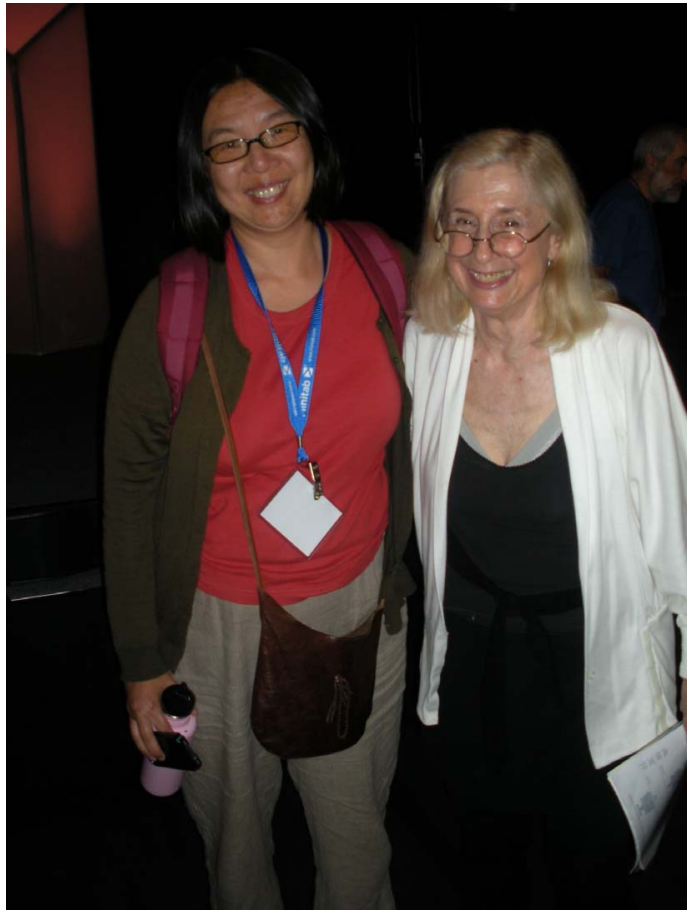

FIG. 7. With Bin Yu, JSM, 2014.

and he was doing some classification problems and he had a wonderful dataset, some slides of tumors. He was building a classification algorithm to determine whether they were cancers or not. He would complain that, "The statisticians don't know what I am doing but my method is very successful." He tried to explain it to me and I didn't know what he was talking about. We agreed that we did not understand what each other was doing! So it was clear there was a gap in the knowledge there.

But then there was this meeting at Mount Holyoke College and we had a session sitting out on the grass. Vapnik got up and talked first, and he wrote down something that looks like an optimization problem in an RKHS. David Donoho (at least I think it was Donoho) said, "That looks like Grace Wahba's stuff." Then my turn came in and I put up a RKHS and it became evident that you can get the SVM as the solution to an optimization problem in a Reproducing Kernel Hilbert Space! You just have to replace the sum of squares in the penalized likelihood term with the hinge function.

Four of us: Myself, Yi Lin, then an assistant professor at Madison and Hao Helen Zhang, and Yoonkyung Lee, then students, now full professors, started batting around the SVM and why it worked so well-something that was quite mysterious at the time. Several papers eventually were written $[8-10,20]$ from different subsets of the four, including a numerical demonstration and a purely theoretical proof that the SVM was estimating the sign of the log odds ratio. That's exactly what you want. I can't tell you whose idea that was because it came out of discussions among all four of us.
Then there was the business about multicategory SVMs. You can do a multicategory SVMs by comparisons, making a lot of pairwise comparisons if you want and we batted that around. There were also some attempts in the literature to obtain a true multicategory SVM in a single optimization problem, but without much success. Someone in the group said, "Let's do a true multicategory SVM in one optimization problem." Somebody (likely Yoon) piped up that the trick was to code a sum-to-zero constraint when training the model. Suppose you have $K$ categories and suppose the $r$ th category is the correct one. Then that label is a $K$ dimensional vector with 1 in the $r$ th position and $-1 /(K-1)$ in the other positions, so the components sum to zero.

The optimization problem now involves estimating a vector of $K$ functions which sum to zero, and we demonstrated the efficacy of the approach [8].

\section{CREATIVITY IN RESEARCH}

Bates: I want to go back to that remark you made earlier where you said something like, "I'm not really sure where the idea came from or how it came out of the group's discussions." Is it usually how you've worked on your research? Where do your ideas come from?

Wahba: In reflecting back, I realized that Wahba's problem was one of the few pieces of work that was not a survey and where I am the single author. It is mostly like George Kimeldorf and I batting about these ideas around about RKHS and splines. I couldn't figure out who thought of what or thought of it first, but it doesn't really make any difference because it came out of our conversation. We had a situation where we had different skill sets and that has led to a complementary working arrangement. I think some of the time that will come out of collaboration and somehow I made that happen in many papers. It's really fun when a good idea pops out of a conversation.

Bates: You were mentioning that even though you had the experience at IBM, you never wanted to or you haven't learned to program. But you found yourself in these highly applied areas, so it was necessary to have the people around, where you could have them program computational methods. The important thing that you mentioned was that you knew what the answer should look like. People often lack the ability to know approximately what this long complicated computation should end up producing as a result. That is a very valuable thing. One person can do the detail stuff but you also have that overview of what to expect.

Wahba: You are right. One of my students programmed a toy meteorological problem. It involved the 2D barotropic vorticity equation reduced to action on a latitude circle. It had all the parts of a prediction model: a differential equation model of the atmosphere, simulated data 


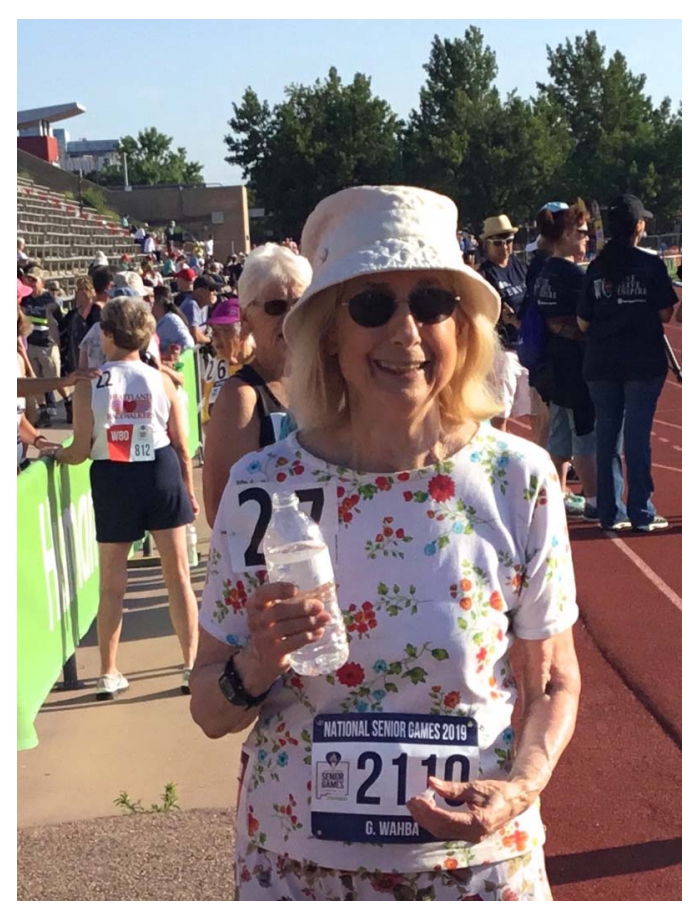

FIG. 8. At the National Senior Games in Albuquerque, June 2019, waiting for the $W 1500$ racewalking event to begin.

and a simulated forecast. I was trying to show that you could estimate two free parameters in the barotropic vorticity equation along with other tuning parameters.

Nychka: We would call that now calibration of a computer model and you were about 20 years ahead of the field. How did it work out?

Wahba: Everything had reasonable meteorological units. We did it all carrying those units through the equations. So I had a very good idea as to what the prediction error should be. My student kept getting errors that the root mean squared error was off by some factor around 6. I said, "This is impossible; the answers have physical units," because I knew what was sensible. Eventually, we found a missing $2 \pi$ !

\section{TRAINING THE NEXT GENERATION AND THE FUTURE OF STATISTICAL SCIENCE}

Nychka: So, here is a tough question. What is your secret for mentoring students?

Wahba: Well you have seen it for yourself. It is purely dependent on each student.

Nychka: Many faculty are available to students but they're just not as successful.

Wahba: I don't know, but I guess I don't have a formula. I just think that having really good students is great. I mean you had a great Ph.D. project. Just seeing how it worked out was rewarding. I wouldn't have thought of any of those things you did.

Ma: OK Grace, another hard question. What do you think is the future of statistics? Do you think we're going

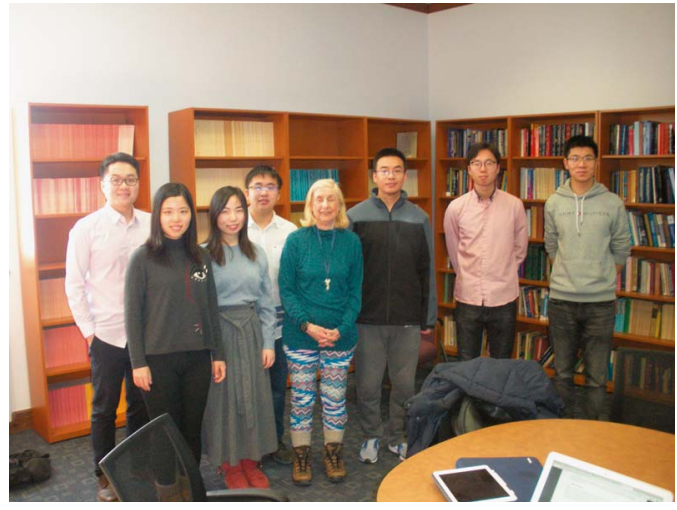

FIG. 9. The Monday Group-Students take turns presenting their research, followed by audience critiques, February 2019. Left to right: Xiaowu Dai, Yilin Zhang, Lili Zheng, Yuchen Zhou, me, Hao Zhou, Rungang Han, Yuetian Luo.

to still have a distinct field in 10 years or will it all be machine learning and data science?

Wahba: First of all, you can interpret that question in multiple ways. One interpretation is, "What is the future of academic statistics departments?". That is one question. I think it involves collaborations. Here in Madison, we have a Computer Sciences Department where we have some joint appointments and we also have affiliations in Biostatistics and Medical Informatics. Also, some people here in Electrical and Computer Engineering are doing statistics-like stuff that you could call machine learning. The idea of George Box was that statistics should be in the middle of the scientific enterprise. So, there are two kinds of collaborations, one is with all the departments that I have just talked about. They all collaborate on the development of methods. They all have knowledge, people in there have the knowledge that will contribute to statistical knowledge and developing new methods. For example, the CS people know how to deal with huge datasets.

The other kind of collaboration is with subject matter people who are collecting data. That's just about every field you can think of-astronomy, physics, sociology, journalism, even historians, and not to mention medical researchers. So academic departments that want to be relevant will involve collaboration with other departments interested in methods development and a wide variety of disciplines that are or should be collecting data. The old model that I grew up in was that statistics was a branch of mathematics, that's all we could do a lot of the time. We spent time studying probability and we had all kinds of beautiful results on random processes. It didn't have too much to do with applications. Of course, big data was unknown when I got my Ph.D. in 1966. Also unavailable was the possibility of solving a ten-by-ten linear system. But still people need to prove theorems and have a theoretical understanding of what is going on. But I think the future is involved more in applications. 


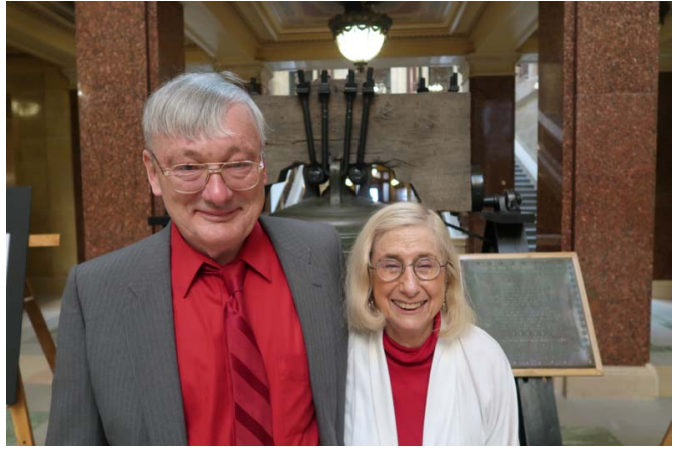

FIG. 10. David and Grace before their wedding in front of the Liberty Bell in the Wisconsin State Capitol Rotunda, after a 30-year engagement, November 10, 2017.

\section{IN CLOSING}

Nychka: Grace, from these stories I am impressed by how you overcame many obstacles that were not there for men in the field. Have things gotten better for women in science?

Wahba: Well, I got a Stanford Ph.D. as a single mom with a son and an essentially full-time job. I was working hard.

Times have really changed but you still have substantial gender disparity in income. People used to ask me if I am a feminist. I would tell them that I was already liberated. So, I would say, "yes, things have become better, but we shouldn't relax yet. There are still things, more to do." Well, there was a couple that worked at ORI. They were both working on their masters. She typed both of their theses. I said, "Jeez, they should have hired somebody. How unfair!" The idea that husbands and wives have equal opportunity to pursue education and career was, roughly, nonexistent then. Times have seriously changed for the better.

Ma: But even back then you somehow seemed to find solutions for your professional advancement and built a wonderful career.

Wahba: For me, it was all right. There were very few bumps along the way. I think it helps that you work very hard and you enjoy it. Yeah. That is my advice to young people. First of all, you need to find something that really you love and then do everything you can to preserve that. There's no easy road to be creative, I think.

Nychka: I think you're very creative.

Wahba: Well I thought about my formula. Hard work, a little bit of luck, a little bit of talent and a lot of help from my friends, students and professors.

Ma: Grace, thanks so much for sharing your time and sharing these stories of your life.

\section{ACKNOWLEDGMENTS}

The authors thank: the members of Big Data Analytics Lab at University of Georgia, Carolyn Freedman and
David Callan, for their valuable help in transcription and editing this conversation.

\section{REFERENCES}

[1] Box, G. E. P., Hunter, W. G. and Hunter, J. S. (1978). Statistics for Experimenters: An Introduction to Design, Data Analysis, and Model Building. Wiley Series in Probability and Mathematical Statistics. Wiley, New York. MR0483116

[2] Craven, P. and WahbA, G. (1978/79). Smoothing noisy data with spline functions. Estimating the correct degree of smoothing by the method of generalized cross-validation. Numer. Math. 31 377-403. MR0516581 https://doi.org/10.1007/BF01404567

[3] Golub, G. H., Heath, M. and Wahba, G. (1979). Generalized cross-validation as a method for choosing a good ridge parameter. Technometrics 21 215-223. MR0533250 https://doi.org/10.2307/1268518

[4] Gong, J., Wahba, G., Johnson, D. and Tribbia, J. (1998). Adaptive tuning of numerical weather prediction models: Simultaneous estimation of weighting, smoothing and physical parameters. Mon. Weather Rev. 126 210-231.

[5] Kimeldorf, G. and WahBA, G. (1971). Some results on Tchebycheffian spline functions. J. Math. Anal. Appl. 33 82-95. MR0290013 https://doi.org/10.1016/0022-247X(71)90184-3

[6] Kimeldorf, G. S. and WahbA, G. (1970). A correspondence between Bayesian estimation on stochastic processes and smoothing by splines. Ann. Math. Stat. 41 495-502. MR0254999 https://doi.org/10.1214/aoms/1177697089

[7] Kimeldorf, G. S. and WAHBA, G. (1970). Spline functions and stochastic processes. Sankhya, Ser. A 32 173-180. MR0303594

[8] LeE, Y., Lin, Y. and Wahba, G. (2004). Multicategory support vector machines: Theory and application to the classification of microarray data and satellite radiance data. J. Amer. Statist. Assoc. 99 67-81. MR2054287 https://doi.org/10.1198/ 016214504000000098

[9] LiN, Y., LEE, Y. and WAHBA, G. (2002). Support vector machines for classification in nonstandard situations. Mach. Learn. 46 191-202.

[10] Lin, Y., WAHBA, G., ZhANG, H. and LEE, Y. (2002). Statistical properties and adaptive tuning of support vector machines. Mach. Learn. 48 115-136.

[11] Nychka, D., Wahba, G., Goldfarb, S. and Pugh, T. (1984). Cross-validated spline methods for the estimation of three-dimensional tumor size distributions from observations on two-dimensional cross sections. J. Amer. Statist. Assoc. 79 832846. MR0770276

[12] O'Sullivan, F. and WAHBA, G. (1985). A cross validated Bayesian retrieval algorithm for non-linear remote sensing. $J$. Comput. Phys. 59 441-455.

[13] PARzen, E. (1960). Modern Probability Theory and Its Applications. A Wiley Publication in Mathematical Statistics. Wiley, New York. MR0112166

[14] PARZEN, E. (1962). Stochastic Processes. Holden-Day Series in Probability and Statistics. Holden-Day, San Francisco, CA. MR0139192

[15] VAN DER WAERDEN, B. L. (1953). Algebra. Vol 1. Ungar, New York.

[16] WahBA, G. (1965). Problem 65-1, a least squares estimate of satellite attitude: Problem proposal. SIAM Rev. 7409.

[17] WahbA, G. (1966). Problem 65-1, a least squares estimate of satellite attitude. SIAM Rev. 8 384-386. 
[18] WahBA, G. (1977). Practical approximate solutions to linear operator equations when the data are noisy. SIAM J. Numer. Anal. 14 651-667. MR0471299 https://doi.org/10.1137/0714044

[19] Wahba, G. (1987). Three topics in ill-posed problems. In Inverse and Ill-Posed Problems (Sankt Wolfgang, 1986). Notes Rep. Math. Sci. Engrg. 4 37-51. Academic Press, Boston, MA. MR1020307 https://doi.org/10.1016/B978-0-12-239040-1. 50008-9

[20] Wahba, G., Lin, Y., Lee, Y. and Zhang, H. (2003). Optimal properties and adaptive tuning of standard and nonstandard support vector machines. In Nonlinear Estimation and
Classification (Berkeley, CA, 2001). Lect. Notes Stat. 171 129147. Springer, New York. MR2005787 https://doi.org/10.1007/ 978-0-387-21579-2_8

[21] Wahba, G. and Wendelberger, J. (1980). Some new mathematical methods for variational objective analysis using splines and cross-validation. Mon. Weather Rev. 108 1122-1145.

[22] WahBA, G. and Wold, S. (1975). A completely automatic French curve: Fitting spline functions by cross validation. Commun. Stat. 4 1-17. MR0655432 https://doi.org/10.1080/ 03610917508548493 